\title{
U-Model-Based Active Disturbance Rejection Control for the Dissolved Oxygen in a Wastewater Treatment Process
}

\author{
Wei Wei (D), ${ }^{1,2,3}$ Nan Chen, ${ }^{1,2,3}$ Zhiyuan Zhang, ${ }^{1,2,3}$ Zaiwen Liu, ${ }^{1,2,3}$ and Min Zuo $\mathbb{D}^{1,2,3}$ \\ ${ }^{1}$ School of Computer and Information Engineering, Beijing Technology and Business University, Beijing 100048, China \\ ${ }^{2}$ National Engineering Laboratory for Agri-Product Quality Traceability, Beijing Technology and Business University, \\ 100048 Beijing, China \\ ${ }^{3}$ Beijing Key Laboratory of Big Data Technology for Food Safety, Beijing 100048, China \\ Correspondence should be addressed to Min Zuo; zuomin@btbu.edu.cn
}

Received 24 February 2020; Revised 30 March 2020; Accepted 13 April 2020; Published 25 May 2020

Academic Editor: Quanmin Zhu

Copyright (c) 2020 Wei Wei et al. This is an open access article distributed under the Creative Commons Attribution License, which permits unrestricted use, distribution, and reproduction in any medium, provided the original work is properly cited.

\begin{abstract}
Dissolved oxygen (DO) concentration is a key variable in wastewater treatment process (WWTP). It directly influences effluent quality of a wastewater treatment. However, due to the great changes of the influent flow rate and the large uncertainties of the wastewater in composition, concentration, and temperature, most control approaches become powerless on DO regulation. To improve the robustness of a DO control, and reduce the phase delay between the control input and the system output, a U-modelbased active disturbance rejection control (UADRC) is proposed. The U-model control (UC) reduces the phase delay between the control input and the system output. The active disturbance rejection control (ADRC) enhances the robustness of the closed-loop system. Also, ADRC converts the system dynamics to be integrators connected in series, which helps the realization of UC. By changing the system dynamics to be an approximate unit, a controller based on desired closed-loop system dynamics can be designed and the DO concentration is guaranteed. UADRC combines advantages of both UC and ADRC, and a commonly accepted benchmark simulation model no.1 (BSM1) is taken to verify the proposed UADRC. Numerical results show that, with similar energy consumption, the UADRC is able to achieve much better tracking performance than ADRC, SMC, and PI with suggested parameters.
\end{abstract}

\section{Introduction}

Water crisis may occur. If it happens, it will have great impact on human's life [1]. Wastewater treatment is an approach to deal with water shortage, and wastewater treatment process (WWTP) control has been widely concerned from all over the world [2-4]. Dissolved oxygen (DO) concentration is a key variable in a WWTP, which directly affects growth and metabolism of the microbes, and determines the wastewater treatment performance [5]. However, DO concentration is influenced by many factors, such as the influent flow rate, the components, the concentration of each component, and reaction temperature. The influent flow rate is not fixed; it may vary due to various factors. Wastewater components and their concentrations are also unstable, or even some of them are unavailable. Therefore, there are too many uncertainties in a WWTP, and it is difficult to build an accurate mathematical model to describe a WWTP. Those facts present great challenges to keep a desired DO concentration level.

To improve the wastewater treatment performance, in recent years, various control approaches have been proposed to regulate the DO concentration. Zhang et al. [6] proposed a distributed economic model predictive control strategy for a WWTP, simulation results showed that the proposed control strategy is able to significantly reduce the computation load with a little degradation of the control performance. Santín et al. presented a model predictive control (MPC) with inlet flow rate feedforward (FF) control (MPC $+\mathrm{FF})$ for the lower level nitrate nitrogen and DO control in a WWTP [7]. Numerical results demonstrated that MPC + FF can achieve a satisfied control performance. Han et al. [8] designed a selforganizing sliding-mode controller to control the DO concentration, and a desired operation performance was achieved. 
In addition, for the sake of improving the robustness of a WWTP control, approaches that depend less on model information, such as data driven control $[9,10]$, sliding-mode control (SMC) $[11,12]$, active disturbance rejection control (ADRC) [13-15], and fuzzy neural network (FNN) [16, 17], were proposed.

Actually, considering the ubiquitous uncertainties and disturbances existing in a WWTP, control approaches that depend less on system model attract much attention in recent years. However, among those results, few of them take the phase delay resulting from system's relative degree into consideration, while, the relative degree of a controlled plant introduces the phase delay, which does result in time delay of the system response or even instability of a system. To reduce the phase delay resulting from the relative order, the U-model control (UC) has been proposed [18]. Its main idea is to build a dynamic inverse model for a controlled plant, and then the controlled plant is dynamically transferred to be a unit. In other words, by $\mathrm{UC}$, there is no phase delay between the control input and system output. By eliminating the phase delay, system responses can be greatly improved. However, for UC, both uncertainties and the $\mathrm{U}$-model invertibility need to be considered properly [19].

Therefore, in this paper, both system responses and the closed-loop robustness are considered in the design of DO concentration regulation. The $\mathrm{UC}$ is able to reduce the phase delay of a controlled plant, improve the system response and tracking accuracy. The active disturbance rejection control (ADRC) proposed by Han [20] is capable of estimating and cancelling out the total disturbance actively so as to guarantee a desired system output. Based on the facts above, a U-model based active disturbance rejection control (UADRC) is proposed. By ADRC, the total disturbance is estimated by an extended state observer (ESO), and it can be compensated actively, so that the system dynamics can be converted into integrators connected in series. As long as the ESO works expectantly, robustness can be guaranteed. Then, the system inverse model becomes differentiators connected in series, and the U-model control can be realized. It means that the phase delay can be reduced. Therefore, the UADRC inherits advantages of both UC and ADRC. Both system responses and robustness can be guaranteed by the UADRC in DO concentration control. Main contribution of the work can be summarized as

(i) A U-model based active disturbance rejection control is proposed. The UADRC reduces the phase delay between control input and system output. System response rate is faster, tracking error becomes much smaller, and the closed-loop system is more robust to disturbances and uncertainties.

(ii) The UADRC solves the concerns of uncertainties and invertibility in the U-model control.

(iii) The UADRC provides a frame to preset desired closed-loop system performance. Based on such a flexible structure, a control law can be designed according to the desired closed-loop system dynamics, and the tracking performance can be greatly improved.

(iv) The UADRC proposed is verified by a commonly accepted BSM1, and the DO concentration is controlled as desired.

\section{Problem Description}

2.1. The Wastewater Treatment Model. The benchmark simulation model no.1 (BSM1) is under the umbrella of the International Water Association (IWA) Task Group on benchmarking of control strategies for WWTPs [21]. It is an accepted platform to test the innovating control strategies via fair comparisons based on a defined set of criteria [21]. In other words, it is a standardized "simulation benchmark," which provides an impartial basis for evaluating past, present, and future control strategies for a WWTP control without reference to a particular facility [22]. Therefore, in this paper, the BSM1 is taken as the test platform. Structure of the BSM1 is given in Figure 1 [21-23].

From Figure 1, one can see that the BSM1 is comprised of a biological reactor and a clarifier. Biological reactions take place in the biological reactor, and they are described by the Activated Sludge Model no.1 (ASM1). The biological reactor consists of five units. The first two units are anoxic sections (the volume of each unit is $1000 \mathrm{~m}^{3}$ ), and the last three units are aerated sections (the volume of each unit is $1333 \mathrm{~m}^{3}$ ). By manipulating the oxygen transfer coefficient $\left(K_{\mathrm{La}, 5}\right)$ of the last aerated reactor, a PI control is designed to control the dissolved oxygen concentration in the last aerated unit. Simultaneously, by manipulating the internal recycle flow rate $\left(Q_{a}\right)$, the nitrate concentration in the second anoxic reactor is regulated by a PI controller [21]. For convenience, all variables and acronyms are summarized in Table 1.

2.2. Control Problem Statement. DO concentration in the fifth unit is one of the key variables in a WWTP. It directly affects the effluent of the wastewater treatment. In practice, for a WWTP, the DO concentration is affected by many factors, such as the influent flow rate, the components, and the concentration of each component in the wastewater [21]. However, the influent flow rate varies, the component differs, and the concentration of each component fluctuates. Therefore, it is difficult to build an accurate model for a WWTP. How to achieve an effective regulation of DO concentration in a WWTP is still a great challenge.

Thus, the aim of this paper is to design a control algorithm so that it can regulate the DO concentration at the set-value accurately, and influence of a control strategy on process performance is expected to be robust enough to different disturbances. Simultaneously, if possible, lower energy consumption is better.

\section{U-Model Based Active Disturbance Rejection Control}

Too many uncertainties make the control of DO concentration a big challenge. In this section, the U-model control 


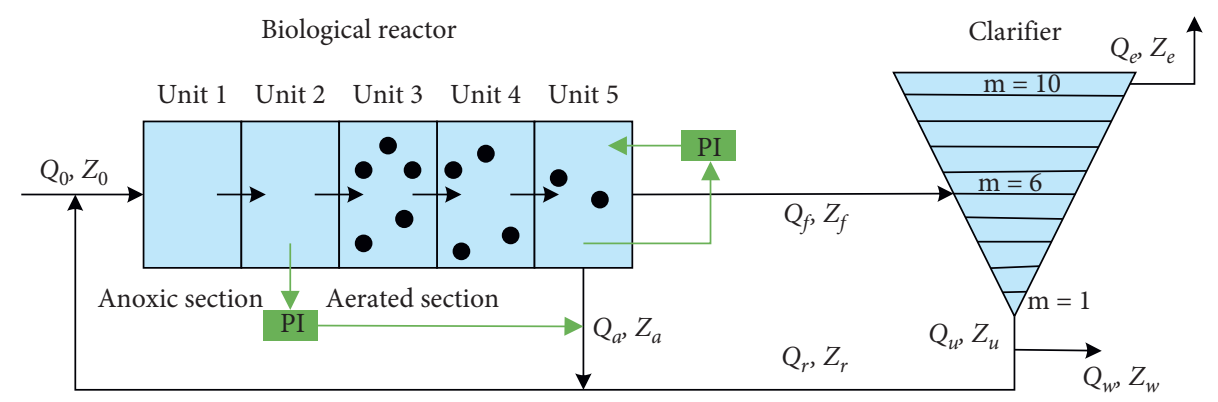

FIGURE 1: Layout of the BSM1.

TABLE 1: List of variables in BSM1.

\begin{tabular}{|c|c|}
\hline$Q_{0}$ & Inlet flow rate \\
\hline$Z_{0}$ & Influent constituent concentration \\
\hline$Q_{a}$ & Internal flow recirculation rate \\
\hline$Z_{a}$ & Internal flow constituent concentration \\
\hline$Q_{r}$ & Return sludge flow rate \\
\hline$Z_{r}$ & Return sludge constituent concentration \\
\hline$Q_{f}$ & Flow rate to the secondary clarifier \\
\hline$Z_{f}$ & $\begin{array}{l}\text { Constituent concentration of the wastewater to the } \\
\text { secondary clarifier }\end{array}$ \\
\hline$Q_{u}$ & Underflow rate of the secondary clarifier \\
\hline$Z_{u}$ & $\begin{array}{l}\text { Constituent concentration of the underflow rate of the } \\
\text { secondary clarifier }\end{array}$ \\
\hline$Q_{w}$ & Wastage flow rate \\
\hline$Z_{w}$ & Wastage constituent concentration \\
\hline$Q_{e}$ & Effluent flow rate \\
\hline$Z_{e}$ & Effluent constituent concentration \\
\hline$S_{O, i}$ & Oxygen concentration at compartment $i$ \\
\hline$K_{L a, i}$ & Oxygen transfer coefficient at compartment $i$ \\
\hline $\mathrm{AE}$ & Aeration energy \\
\hline $\mathrm{PE}$ & Pump \\
\hline SP & Sludge production to be disposed \\
\hline $\mathrm{ME}$ & Mixing energy \\
\hline $\mathrm{EC}$ & Consumption of external carbon source \\
\hline TSS & Suspended solid concentration \\
\hline$V_{i}$ & Volume of the tank $i$ \\
\hline$X_{S, i}$ & Slowly biodegradable substrate concentration at tank $i$ \\
\hline$X_{I, i}$ & Particulate inert organic matter concentration at tank $i$ \\
\hline$X_{B, H, i}$ & Active heterotrophic biomass concentration at tank $i$ \\
\hline$X_{B, A, i}$ & Active autotrophic biomass concentration at tank $i$ \\
\hline$X_{P, i}$ & $\begin{array}{l}\text { Particulate products arising from biomass decay } \\
\text { concemtration at tank } i\end{array}$ \\
\hline$r_{5}$ & Appropriate conversion rate \\
\hline
\end{tabular}

and the active disturbance rejection control are combined, and a U-model-based active disturbance rejection control is designed to regulate the DO concentration in a WWTP.

3.1. Dynamics of the DO Concentration. In the BSM1, DO concentration of unit 5, i.e., $S_{O, 5}$, can be described as $[21,24]$

$$
\dot{S}_{O, 5}=\frac{Q_{0}+Q_{r}+Q_{a}}{V_{4}} S_{O, 4}+r_{5}+K_{\mathrm{La}, 5}\left(S_{O}^{*}-S_{O, 5}\right)-\frac{Q_{0}+Q_{r}+Q_{a}}{V_{5}} S_{O, 5},
$$

where $S_{O, 5}, S_{O, 4}$, and $S_{O}^{*}$ are the DO concentration in the fifth compartment, the DO concentration in the fourth compartment, and the saturation concentration for oxygen, respectively. $V_{4}$ and $V_{5}$ are the volume of the fourth and fifth compartments, separately. $r_{5}$ is an appropriate conversion rate. $K_{\mathrm{La}, 5}$ is the oxygen transfer rate, it is the control input for regulating $S_{O, 5} \cdot Q_{0}, Q_{r}$, and $Q_{a}$ are the input flow rate, the return sludge flow rate, and the internal flow recirculation rate, respectively.

3.2. Control Law Design. Based on the idea of ADRC, system dynamics differs from the integrators connected in series is regarded as the total disturbance. Thus, system (1) can be rewritten as

$$
\dot{y}=f+b_{0} u
$$

where $y=S_{O, 5}$ is the system output, $u=K_{\mathrm{La}, 5}$ is the control input, $b_{0}$ is a tunable parameter, and $f$ is the total disturbance,

$$
\begin{aligned}
f= & \frac{Q_{0}+Q_{r}+Q_{a}}{V_{4}} S_{O, 4}+r_{5}+K_{\mathrm{La}, 5}\left(S_{O}^{*}-S_{O, 5}\right) \\
& -\frac{Q_{0}+Q_{r}+Q_{a}}{V_{5}} S_{O, 5}-b_{0} K_{\mathrm{La}, 5} .
\end{aligned}
$$

The total disturbance $f$ in system (2) can be estimated by an ESO, and it can be designed as [25]

$$
\left\{\begin{array}{l}
\varepsilon_{1}=y-z_{1}, \\
\dot{z}_{1}=z_{2}+\beta_{1} \cdot \varepsilon_{1}+b_{0} u, \\
\dot{z}_{2}=\beta_{2} \cdot \varepsilon_{1}
\end{array}\right.
$$

where $b_{0}, \beta_{1}, \beta_{2}$ are tunable parameters of an ESO. $z_{1}, z_{2}$ are outputs of an ESO. $z_{1}$ is the estimation of the system output $y . z_{2}$ is the estimation of the total disturbance $f . \varepsilon_{1}$ is the estimation error of the system output.

Here, similar to [25], let $\beta_{1}=2 \omega_{o}, \beta_{2}=\omega_{o}^{2}$, where $\omega_{o}$ is the observer bandwidth.

The control law is designed to be

$$
u=\frac{u_{0}-z_{2}}{b_{0}}
$$

where $u$ is the control signal applied to the controlled plant, and $u_{0}$ is a pseudocontrol signal. Substituting (5) into (2), one has 


$$
\dot{y}=f-z_{2}+u_{0} \approx u_{0} .
$$

Obviously, the total disturbance is cancelled out by control law (5), and system (1) is converted to be an integrator approximately.

Let the total disturbance estimation error be $\varepsilon=f-z_{2}$, and the system output estimation error be $\varepsilon_{1}=y-z_{1}$. Then, closed-loop system (6) can be rewritten as

$$
\dot{y}=f-z_{2}+u_{0}=u_{0}+\varepsilon .
$$

Based on (7), a structure of the controlled process is given in Figure 2.

According to the idea of the U-model control, the controlled process should be transferred to be a unit. Thus, a differentiator should be introduced, and it can be shown in Figure 3.

Here, $u^{*}(t)$ is a control signal needed to be designed. Then, an equivalent structure of Figure 3 is given in Figure 4.

Based on the equivalent structure of the UC based controlled process (presented in Figure 4), a closed-loop system can be designed. Its structure is shown in Figure 5.

In Figure 5, $r(t)$ is the set-value, $\widetilde{e}(t)$ is the control error, $C(s)$ is the controller that is needed to be designed, and $u^{*}(t)$ is the output of $C(s) . \varepsilon, \varepsilon_{1}$ are estimation errors.

From Figure 5, one can see clearly that, ideally, i.e., $\varepsilon(t)=\varepsilon_{1}(t)=0$, the closed-loop system dynamics can be flexible designed according to the desired system response.

To achieve a faster response, the desired closed-loop system dynamics is chosen to be

$$
\Phi(s)=\frac{\tau_{n} s+\omega_{n}^{2}}{s^{2}+\tau_{n} s+\omega_{n}^{2}},
$$

then controller $C(s)=\left(\tau_{n} s+\omega_{n}^{2}\right) / s^{2}$; here, $\tau_{n}, \omega_{n}$ are parameters that need to be fixed. Thus, $u^{*}(t)$ can be designed as

$$
u^{*}(t)=\tau_{n} \int\left(r-z_{1}\right) \mathrm{d} t+\omega_{n}^{2} \iint\left(r-z_{1}\right) \mathrm{d} t
$$

Then, the UADRC control system can be realized, and it is shown in Figure 6. It is based on the ESO and the U-model based controller $G_{c}(s)$.

From Figure 6, one has

$$
G_{c}(s)=\tau_{n}+\frac{\omega_{n}^{2}}{s} .
$$

Then,

$$
u_{0}=\tau_{n}\left(r-z_{1}\right)+\omega_{n}^{2} \int\left(r-z_{1}\right) \mathrm{d} t
$$

whereris a set-value.

In summary, the UADRC consists of the observer (4), control law (5), and (11).

\subsection{Closed-Loop System Analyses}

3.3.1. Stability and Tracking Error. Figure 5 gives out the closed-loop structure of the UADRC control system, from which one can see that the closed-loop system is affected by

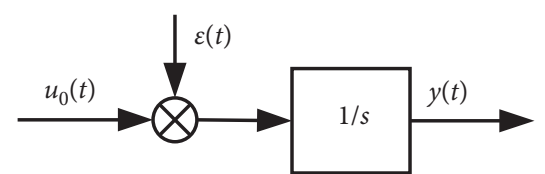

Figure 2: Structure of the controlled process.

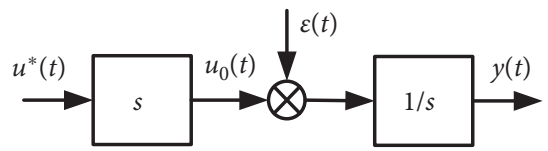

Figure 3: U-model control based controlled process.

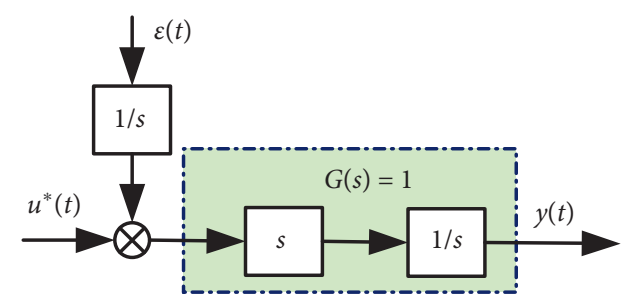

Figure 4: An equivalent structure of Figure 3.

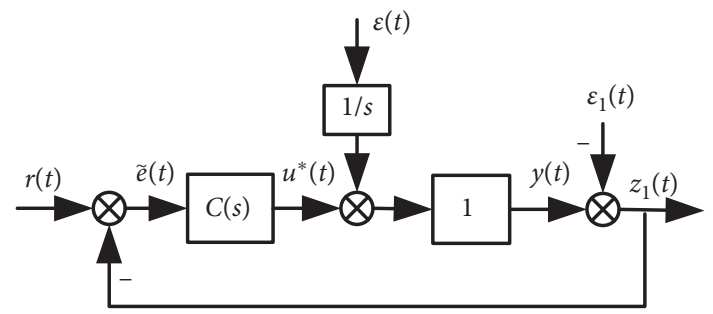

Figure 5: An equivalent U-model-based active disturbance rejection control system.

three signals, i.e., the reference signal $r$, the total disturbance estimation error $\varepsilon$, and the system output estimation error $\varepsilon_{1}$.

The closed-loop system presented in Figure 5 is a linear system. If the closed-loop poles of $\Phi(s)$ given in (8) are on the left side of $s$-plane, the closed-loop system is stable.

Remark 1. Nonlinearities, uncertainties, and disturbances in the system are addressed by the ESO. Their effects are reflected on two inputs including the total disturbance estimation error $\varepsilon$ and the system output estimation error $\varepsilon_{1}$.

Next, influence of $\varepsilon$ and $\varepsilon_{1}$ on the closed-loop system output is analyzed.

For the ESO, one has following Lemma.

Lemma 1 (see [26]). If change rate of the total disturbance is bounded, there exists an observer bandwidth $\omega_{o}^{*}$ such that estimation errors of an ESO are bounded within a finite time. Additionally, bounds of estimation errors are inversely proportional to the observer bandwidth. 


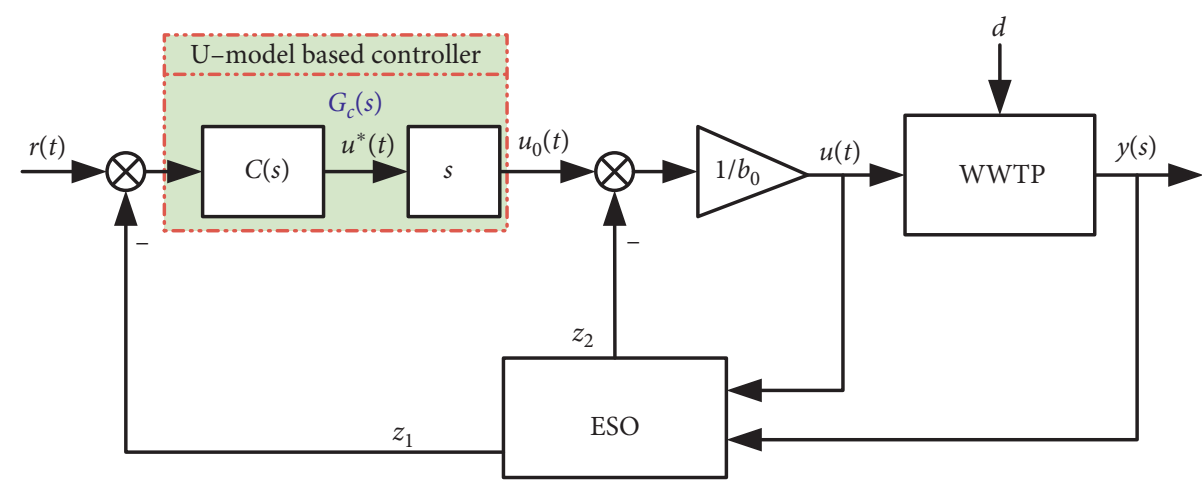

FIGURE 6: Structure of a UADRC control system.

Remark 2. For an engineering system, its power is always limited. Therefore, it is reasonable to assume that the change rate of the total disturbance is bounded.

According to the Lemma, one has $|\varepsilon| \leq \sigma,\left|\varepsilon_{1}\right| \leq \sigma$. Here, $\sigma>0$ is a constant, which is inversely proportional to the observer bandwidth. In other words, both $\varepsilon$ and $\varepsilon_{1}$ are bounded input signals for the closed-loop system given in Figure 5. Then, system output $y$ can be obtained by the superposition principle, i.e.,

$$
\begin{aligned}
y(s)= & y_{r}(s)+y_{\varepsilon}(s)+y_{\varepsilon_{1}}(s) \\
= & \frac{\tau_{n} s+\omega_{n}^{2}}{s^{2}+\tau_{n} s+\omega_{n}^{2}} r(s)+\frac{s}{s^{2}+\tau_{n} s+\omega_{n}^{2}} \varepsilon(s) \\
& +\frac{-\left(\tau_{n} s+\omega_{n}^{2}\right)}{s^{2}+\tau_{n} s+\omega_{n}^{2}} \varepsilon_{1}(s) .
\end{aligned}
$$

Considering $\varepsilon, \varepsilon_{1}$ are bounded, one may let $y(t)=y_{r}(t)+y_{\varepsilon}(t)+y_{\varepsilon_{1}}(t)$

$\varepsilon=\sigma \sin \omega t, \varepsilon_{1}=\sigma \sin \omega_{1} t$. For $r(t)=A \cdot 1(t) \quad(A$ is the where amplitude, and $1(t)$ is the unit step signal), one has

$$
\begin{aligned}
& y_{r}(t)=A\left[1-e^{-(1 / 2) \tau_{n} t} \cosh \left(\frac{1}{2} t \sqrt{\tau_{n}^{2}-4 \omega_{n}^{2}}\right)+\frac{\tau_{n} e^{-(1 / 2) \tau_{n} t}}{\sqrt{\tau_{n}^{2}-4 \omega_{n}^{2}}} \sinh \left(\frac{1}{2} t \sqrt{\tau_{n}^{2}-4 \omega_{n}^{2}}\right)\right], \\
& y_{\varepsilon}(t)=\sigma \frac{\tau_{n} \omega^{2} \sin (\omega t)-e^{-(1 / 2) \tau_{n} t}\left(\omega \tau_{n}\left(\omega^{2}+\omega_{n}^{2}\right) \sinh \left((1 / 2) t \sqrt{\tau_{n}^{2}-4 \omega_{n}^{2}}\right) / \sqrt{\tau_{n}^{2}-4 \omega_{n}^{2}}\right)+\omega\left(\omega^{2}-\omega_{n}^{2}\right)\left[e^{-(1 / 2) \tau_{n} t} \cosh \left((1 / 2) t \sqrt{\tau_{n}^{2}-4 \omega_{n}^{2}}\right)-\cos (\omega t)\right],}{\tau_{n}^{2} \omega^{2}+\omega^{4}-2 \omega^{2} \omega_{n}^{2}+\omega_{n}^{4}} \\
& y_{\varepsilon_{1}}(t)=-\sigma \frac{\left(\omega_{n}^{4}+\tau_{n}^{2} \omega_{1}^{2}-\omega_{1}^{2} \omega_{n}^{2}\right) \sin \left(\omega_{1} t\right)-\left(\left(\tau_{n}^{2} \omega_{1}^{2}-2 \omega_{1}^{2} \omega_{n}^{2}+2 \omega_{n}^{4}\right) \omega_{1} e^{-(1 / 2) \tau_{n} t} \sinh \left((1 / 2) t \sqrt{\tau_{n}^{2}-4 \omega_{n}^{2}}\right) / \sqrt{\tau_{n}^{2}-4 \omega_{n}^{2}}\right)+\tau_{n} \omega_{1}^{3}\left[e^{-(1 / 2) \tau_{n} t} \cosh \left((1 / 2) t \sqrt{\tau_{n}^{2}-4 \omega_{n}^{2}}\right)-\cos \left(\omega_{1} t\right)\right]}{\tau_{n}^{2} \omega_{1}^{2}+\omega_{1}^{4}-2 \omega_{1}^{2} \omega_{n}^{2}+\omega_{n}^{4}}
\end{aligned}
$$

From (13), it can be seen clearly that both bound $\sigma$ and frequency $\left(\omega, \omega_{1}\right)$ of the estimation error $\varepsilon, \varepsilon_{1}$ have effects on system output. How to reduce the influence of the estimation errors on system output? Next, the tracking error and its steady-state value are analyzed.

The tracking error $e(t)=r(t)-y(t)$, and the steadystate tracking error is

$$
\begin{aligned}
e(\infty) & =\lim _{t \rightarrow \infty}\left[r(t)-y_{r}(t)-y_{\varepsilon}(t)-y_{\varepsilon_{1}}(t)\right] \\
& =\lim _{t \rightarrow \infty}\left(-\sigma \frac{\tau_{n} \omega^{2} \sin (\omega t)-\omega\left(\omega^{2}-\omega_{n}^{2}\right) \cos (\omega t)}{\tau_{n}^{2} \omega^{2}+\omega^{4}-2 \omega^{2} \omega_{n}^{2}+\omega_{n}^{4}}+\sigma \frac{\left(\omega_{n}^{4}+\tau_{n}^{2} \omega_{1}^{2}-\omega_{1}^{2} \omega_{n}^{2}\right) \sin \left(\omega_{1} t\right)-\tau_{n} \omega_{1}^{3} \cos \left(\omega_{1} t\right)}{\tau_{n}^{2} \omega_{1}^{2}+\omega_{1}^{4}-2 \omega_{1}^{2} \omega_{n}^{2}+\omega_{n}^{4}}\right) .
\end{aligned}
$$


Thus,

$$
\begin{aligned}
|e(\infty)| & \leq \sigma\left[\frac{\left(\omega_{n}^{4}+\tau_{n}^{2} \omega_{1}^{2}-\omega_{1}^{2} \omega_{n}^{2}\right)+\tau_{n} \omega_{1}^{3}}{\tau_{n}^{2} \omega_{1}^{2}+\omega_{1}^{4}-2 \omega_{1}^{2} \omega_{n}^{2}+\omega_{n}^{4}}-\frac{\tau_{n} \omega^{2}-\omega\left(\omega^{2}-\omega_{n}^{2}\right)}{\tau_{n}^{2} \omega^{2}+\omega^{4}-2 \omega^{2} \omega_{n}^{2}+\omega_{n}^{4}}\right] \\
& =\sigma\left[\frac{\omega_{n}^{4}+\tau_{n}^{2} \omega_{1}^{2}-\omega_{1}^{2} \omega_{n}^{2}+\tau_{n} \omega_{1}^{3}}{\tau_{n}^{2} \omega_{1}^{2}+\left(\omega_{1}^{2}-\omega_{n}^{2}\right)^{2}}+\frac{\omega^{3}-\tau_{n} \omega^{2}-\omega \omega_{n}^{2}}{\tau_{n}^{2} \omega^{2}+\left(\omega^{2}-\omega_{n}^{2}\right)^{2}}\right] \\
& \leq \sigma\left[\frac{\omega_{n}^{4}+\tau_{n}^{2} \omega_{1}^{2}-\omega_{1}^{2} \omega_{n}^{2}+\tau_{n} \omega_{1}^{3}}{\tau_{n}^{2} \omega_{1}^{2}}+\frac{\omega^{3}-\tau_{n} \omega^{2}-\omega \omega_{n}^{2}}{\tau_{n}^{2} \omega^{2}}\right] \\
& =\sigma\left[\frac{\omega_{n}^{4}}{\tau_{n}^{2} \omega_{1}^{2}}+1+\frac{\omega_{1}}{\tau_{n}}+\frac{\omega}{\tau_{n}^{2}}-\frac{1}{\tau_{n}}-\frac{\omega_{n}^{2}}{\tau_{n}^{2} \omega}-\frac{\omega_{n}^{2}}{\tau_{n}^{2}}\right] \\
& \leq \sigma\left[\frac{\omega_{n}^{4}}{\tau_{n}^{2} \omega_{1}^{2}}+\frac{\omega_{1}}{\tau_{n}}+\frac{\omega}{\tau_{n}^{2}}+1\right],
\end{aligned}
$$

that is

$$
|e(\infty)| \leq \sigma\left[\frac{\omega_{n}^{4}}{\tau_{n}^{2} \omega_{1}^{2}}+\frac{\omega_{1}}{\tau_{n}}+\frac{\omega}{\tau_{n}^{2}}+1\right] .
$$

From (17), one can see that the steady-state tracking error is proportional to the bound of the estimation error. Simultaneously, it is also proportional to $\omega_{n}$ and inversely proportional to $\tau_{n}$.

Remark 3. An ESO is critical in the UADRC. From (17), it is obvious that estimation error of an ESO determine the performance of a closed-loop system greatly. Thus, a proper observer bandwidth should be selected to make the estimation error as small as possible. Then, the controlled plant can be more approximate to be a unit, and the closed-loop dynamics is much closer to the desired dynamics described in (8).

3.3.2. Phase Analysis. From (12), one can see that the output resulting from the set-value $r(s)$ is

$$
y_{r}(s)=\frac{\tau_{n} s+\omega_{n}^{2}}{s^{2}+\tau_{n} s+\omega_{n}^{2}} r(s) .
$$

Thus, one has the frequency response

$$
y_{r}(j \omega)=\frac{\omega_{n}^{2}+j \tau_{n} \omega}{\left(\omega_{n}^{2}-\omega^{2}\right)+j \tau_{n} \omega} r(j \omega) .
$$

If $\omega_{n} \ll \omega, y_{r}(j \omega) \approx\left(\left(\omega_{n}^{2}+j \tau_{n} \omega\right) /\left(\left(-\omega^{2}\right)+j \tau_{n} \omega\right)\right) r(j \omega)$, then the phase lag between the set-value and system output is

$$
\begin{gathered}
\varphi_{\mathrm{UADRC}}=\varphi_{y_{r}}-\varphi_{r}=\arctan \frac{\tau_{n}\left(\omega^{2}+\omega_{n}^{2}\right)}{\omega\left(\omega_{n}^{2}-\tau_{n}^{2}\right)} \\
-\pi \approx \arctan \frac{\tau_{n} \omega}{\left(\omega_{n}^{2}-\tau_{n}^{2}\right)}-\pi .
\end{gathered}
$$

Thus, by increasing $\tau_{n}$ or decreasing $\omega_{n}$, one can reduce the phase delay $\varphi_{\text {UADRC }}$. In this case, the minimum phase delay is $-\pi / 2$, and the maximum phase delay is $-3 \pi / 2$. In other words, $-3 \pi / 2<\varphi_{\mathrm{UADRC}}<-\pi / 2$.
If $\omega_{n} \gg \omega, y_{r}(j \omega) \approx r(j \omega)$, then the phase delay between the set-value and system output is

$$
\varphi_{\mathrm{UADRC}}=\varphi_{y_{r}}-\varphi_{r} \approx 0 .
$$

Thus, nearly no phase delay exists between the setvalue and system output. It means that, when $\omega_{n} \gg \omega$, the UADRC can eliminate the inherent phase delay approximately.

From the analysis above, one can see that no phase delay between the control input and system output can be achieved when $\omega_{n} \gg \omega$. It signifies that, by utilizing the point of the UC, phase lag of the system response can be minimized if $\omega_{n}$ is large enough.

However, the steady-state tracking error is also proportional to $\omega_{n}$. Thus, one has to make a compromise between the system response and the steady-state tracking error.

Therefore, it is obvious that approaches, like improving the estimation ability of an ESO and increasing $\tau_{n}$, are effective in reducing the steady-state tracking error. As to $\omega_{n}$, it can be determined based on the system requirements. In Section 4, numerical results are provided to confirm the UADRC. Before giving out the numerical results, two remarks have been presented.

Remark 4. Similar to the plants controlled by an ADRC, dynamics of a plant controlled by a UADRC is dynamically transferred to be integrators connected in series. Therefore, nonlinearities, uncertainties, and disturbances of a plant are not barriers in realizing the U-model control and guaranteeing desired system performance.

Remark 5. Based on the dynamic feedback linearization of a controlled plant, engineering requirements or desired closed-loop dynamics can be obtained by presetting a desired closed-loop transfer function. Thus, parameters chosen in simulations are determined by compromising desired transient and steady-state performance via try and error approach.

\section{Simulation Studies}

In order to illustrate the advantage of the UADRC, the BSM1 is utilized. It contains influent data of two weeks dynamic dry, rain, and storm weather. Those weather influent data contain the disturbances of influent rates and components. In simulations, all weather conditions are considered, and the input disturbance $(5 \sin (5 t))$ is also introduced from the 7 th day. Two cases, i.e., constant and varying set-values, are designed in the simulations.

4.1. Constant Set-Value of the DO Concentration. In this part, set-value of the DO concentration is $2.0 \mathrm{mg} / \mathrm{l}$, and simulation time lasts 14 days. To show the advantage of the UADRC, PI, SMC, and the ADRC are employed. The SMC control law can be designed as 


$$
u_{\mathrm{SMC}}=\frac{1}{b_{0}}\left(\dot{r}+\eta \cdot \operatorname{sat}(r-y)-\left(\frac{Q_{4} S_{O, 4}}{V_{5}}-\frac{Q_{5} S_{O, 5}}{V_{5}}\right)-D\right),
$$

where $\eta$ is the controller gain, $D$ is a constant, $Q_{4}$ and $Q_{5}$ are flow rate of the fourth and fifth reactors, $S_{O, 4}$ and $S_{O, 5}$ are the dissolved oxygen concentration of the fourth and fifth reactors, and $V_{5}$ is the volume of the fifth compartment.

System responses and performance indexes are presented to confirm the UADRC. In the BSM1, parameters of the PI controller are $K$ and $T_{i}$. Parameters of the SMC are $b_{0}, \eta$ and $D$. Parameters of the ADRC are $\omega_{c}, \omega_{o}$, and $b_{0}$, parameters of the UADRC are $\tau_{n}, \omega_{n}, b_{0}, \omega_{o}$. Tunable parameters of the controllers are listed in Table 2. Here, parameters of the PI control are suggested by Reference [21].

The integral of squared error (ISE) [23], the integral of time-multiplied absolute-value of error (ITAE), and the overall cost index (OCI) [23] are selected to evaluate the tracking performance, the response rate, and the energy consumption, respectively.

$$
\begin{aligned}
\text { ISE } & =\int_{0 \text { days }}^{14 \text { days }} e^{2} \mathrm{~d} t, \\
\text { ITAE } & =\int_{0 \text { days }}^{14 \text { days }} t \cdot|e| \mathrm{d} t,
\end{aligned}
$$

where the tracking error $e=r-y$.

$$
\mathrm{OCI}=\mathrm{AE}+\mathrm{PE}+5 \cdot \mathrm{SP}+3 \cdot \mathrm{EC}+\mathrm{ME},
$$

where $\mathrm{AE}$ is the aeration energy, $\mathrm{PE}$ is the pumping energy, SP is the sludge production to be disposed, EC is the consumption of external carbon source, and ME is the mixing energy. They can be calculated as

$$
\begin{aligned}
& \mathrm{AE}=\frac{S_{O}^{\text {sat }}}{T \cdot 1.8 \cdot 1000} \int_{0 \text { days }}^{14 \text { days }} \sum_{i=1}^{5} V_{i} \cdot K_{L} a_{i}(t) \mathrm{d} t \\
& \mathrm{EC}=\frac{\mathrm{COD}_{\mathrm{EC}}}{T \cdot 1000} \int_{0 \text { days }}^{14 \text { days }}\left(\sum_{i=1}^{i=n} q_{\mathrm{EC}, i}\right) \mathrm{d} t, \\
& \mathrm{ME}=\frac{24}{T} \int_{t=0 \text { days }}^{t=14 \text { days }} \sum_{i=1}^{i=5}\left[\begin{array}{c}
0.005 \cdot V_{i} \\
0
\end{array}\right.
\end{aligned}
$$

$$
\begin{aligned}
& \mathrm{PE}=\frac{1}{T} \int_{t=0 \text { days }}^{t=14 \text { days }}\left(0.004 \cdot Q_{a}(t)+0.008 \cdot Q_{r}(t)\right. \\
&+\left.0.05 \cdot Q_{w}(t)\right) \mathrm{d} t \\
& \mathrm{TSS}_{s}(t)= 0.75 \cdot \sum_{j=1}^{j=10}\left(X_{S, j}+X_{I, j}+X_{B, H, j}+X_{B, A, j}\right. \\
&\left.+X_{P, j}\right) \cdot z_{j} \cdot A,
\end{aligned}
$$

TABle 2: Parameters of four controllers.

\begin{tabular}{lcccc}
\hline Controllers & $K / \omega_{c} / \tau_{n} / \eta$ & $T_{i} / \omega_{o} / D$ & $b_{0}$ & $\omega_{n}^{2}$ \\
\hline PI & 25 & 0.002 & - & - \\
SMC & 4500 & -1300 & 8 & \\
ADRC & 900 & 800 & 8 & - \\
UADRC & 900 & 800 & 8 & 250000 \\
\hline
\end{tabular}

$\operatorname{TSS}_{a}(t)=0.75 \cdot \sum_{i=1}^{i=5}\left(X_{s, i}+X_{I, i}+X_{B, H, i}+X_{B, A, i}+X_{P, i}\right) \cdot V_{i}$,

$$
\operatorname{TSS}(t)=\operatorname{TSS}_{a}(t)+\operatorname{TSS}_{S}(t)
$$

$$
\begin{aligned}
\mathrm{SP}= & \frac{1}{T}\left(\operatorname{TSS}(14 \text { days })-\operatorname{TSS}(0 \text { days })+0.75 \cdot \int_{t=0 \text { days }}^{t=14 \text { days }}\left(X_{S, w}\right.\right. \\
& \left.\left.+X_{I, w}+X_{B, H, w}+X_{B, A, w}\right) \cdot Q_{w}(t) \cdot \mathrm{d} t\right)
\end{aligned}
$$

Details for the parameters in (25) to (32) can be found in [21].

4.1.1. Dry Weather. Under dry weather, system responses and control signals of four controllers are shown in Figure 7. From the figure, it can be found that all control strategies are able to regulate the DO concentration effectively (see Figure 7(a)) with similar control signals (see Figure 7(b)). However, by comparison with the responses of PI, SMC, and ADRC, it can be easily found that the UADRC behaves best. It has the minimum fluctuations in presence of the varying components, influent rates, concentration, and the input disturbance from the 7 th day. Performance indexes (ISE, ITAE), and energy cost index (OCI) are listed and compared in Table 3. Here, "+" stands for the increasing of the corresponding value, and "-" means the decreasing of the value.

From Table 3, one can find following facts. Compared with PI, ISE value of the UADRC decreases by $76.1 \%$, and the ITAE value decreases by $84.0 \%$. It means that the UADRC has much better tracking ability, much faster response rate, and much shorter settling time. Tracking error related indexes (i.e., ISE and ITAE values) show that control approaches based on active estimation and compensation are capable of achieving better tracking performance than PI control with the suggested parameters. Although energy consumption of the UADRC is few higher than the one of PI (increased by $1.0 \times 10^{-3} \%$ ), it should be pointed out that the UADRC is more effective than PI. Similarly, by comparison with SMC, ISE and ITAE values of the UADRC decrease by $70.0 \%$ and $93.5 \%$, respectively. It means that the UADRC is able to track the set-value timelier and more accurately. Additionally, energy consumption of the UADRC also decreases by $2.9 \times 10^{-2} \%$. Finally, compared with the ADRC, with the same observer bandwidth, ISE and ITAE value of the UADRC decreases by $15.6 \%$ and $63.1 \%$, separately. It also confirms that the UADRC can obtain much smaller 


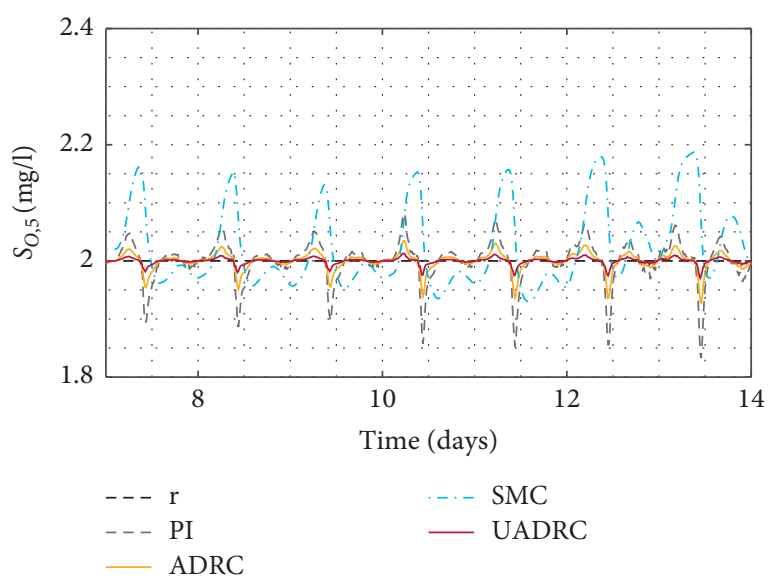

(a)

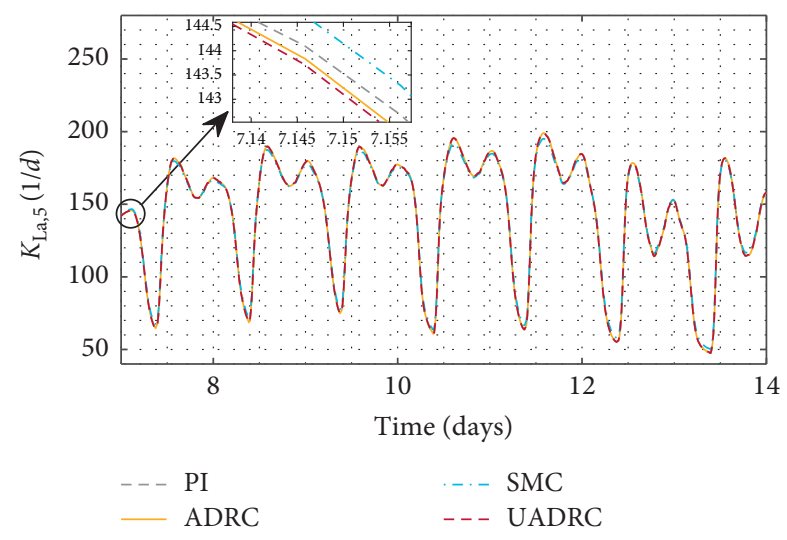

(b)

Figure 7: System responses and control signals for a constant set-value (under dry weather). (a) System responses. (b) Control signals.

TABLE 3: Indexes under dry weather.

\begin{tabular}{lccccccc}
\hline & PI & SMC & ADRC & UADRC & $\begin{array}{c}\text { Improvements } \\
\text { (UADRC vs PI) }\end{array}$ & $\begin{array}{c}\text { Improvements } \\
\text { (UADRC vs SMC) }\end{array}$ & $\begin{array}{c}\text { Improvements } \\
\text { (UADRC vs. ADRC) }\end{array}$ \\
\hline ISE & 0.113 & 0.090 & 0.032 & 0.027 & $-76.1 \%$ & $-70.0 \%$ & $-15.6 \%$ \\
ITAE & 2.085 & 5.134 & 0.903 & 0.333 & $-84.0 \%$ & $-93.5 \%$ & $-63.1 \%$ \\
OCI & 17343.19 & 17348.32 & 17343.40 & 17343.37 & $+1.0 \times 10^{-3} \%$ & $-2.9 \times 10^{-2} \%$ & $-1.7 \times 10^{-4} \%$ \\
\hline
\end{tabular}

tracking errors and much shorter settling time with similar (or exactly few lower) OCI values and similar control signals (see Figure $7(\mathrm{~b})$ ). In other words, by minimizing the phase delay, with similar control signals and energy consumption, the UADRC behaves best.

4.1.2. Rain Weather. For the rain weather, PI, ADRC, SMC, and UADRC are also designed to regulate the DO concentration. Parameters are still taken from Table 2. System responses and control signals are given in Figure 8. ISE, ITAE, and OCI values are listed in Table 4.

It is easy to find that the fluctuations of the UADRC's responses are also minimum among the responses described in Figure 8(a). It means that the UADRC is able to deal with all disturbances more effectively and achieve more accurate tracking responses. Simultaneously, Figure 8(b) shows that the UADRC achieves the best tracking response with similar control signals compared with the SMC, ADRC, and PI.

Table 4 presents similar facts provided in Table 3. The UADRC is able to obtain much better ISE and ITAE values than PI. It coincides with the responses described in Figure 8(a). Similarly, ISE and ITAE values of the UADRC are also much better than the SMC and ADRC, for the minimized phase delay between the control input and system output. It is worth pointing out that few more energies are necessary for the UADRC to acquire better tracking performance and faster response rate.

4.1.3. Storm Weather. The influent file of storm weather contains one week of dynamic dry weather influent data and two storm events superimposed on the dry weather data during the second week. Controller parameters are selected from Table 2. ISE, ITAE, and OCI values are listed in Table 5.

Figure 9 presents the responses and control signals of the PI, SMC, ADRC, and UADRC. From the figure, it is obvious that the UADRC is able to achieve the best tracking performance with similar control signals, even if different kinds of disturbances exist. ISE, ITAE, and OCI values listed and compared in Table 5 also confirm the fact.

Under the storm weather, data presented in Table 5 show that compared with PI, with few more energy consumption (OCI is increased by $9.6 \times 10^{-4} \%$ ), ISE and ITAE values of the UADRC decline by $75.9 \%$ and $83.9 \%$, respectively. Compared with the SMC, ISE, ITAE, and OCI values of the UADRC decrease by $68.2 \%, 93.4 \%$, and $2.8 \times 10^{-2} \%$, respectively. By comparison with ADRC, lower energy (OCI decreases by $2.3 \times 10^{-4} \%$ ) is needed by the UADRC, and ISE and ITAE values of the UADRC decline by $15.6 \%$ and $62.8 \%$. Simultaneously, similar to dry and rain weather, the UADRC behaves best for its much smaller ISE and ITAE values and similar OCI values.

4.2. Varying Set-Values of the DO Concentration. In this part, varying set-values of the DO concentration are taken into consideration. Simulation time is also 14 days. PI, SMC, and ADRC are also employed to make a comparison with the UADRC. Tunable parameters of the four controllers can still be found in Table 2. Dry, rain, and storm weather conditions are considered. As described in Section 4.1, the input disturbance $(5 \sin (5 t))$ is also introduced from the 7 th day. The changing set-values of DO concentration are described as 


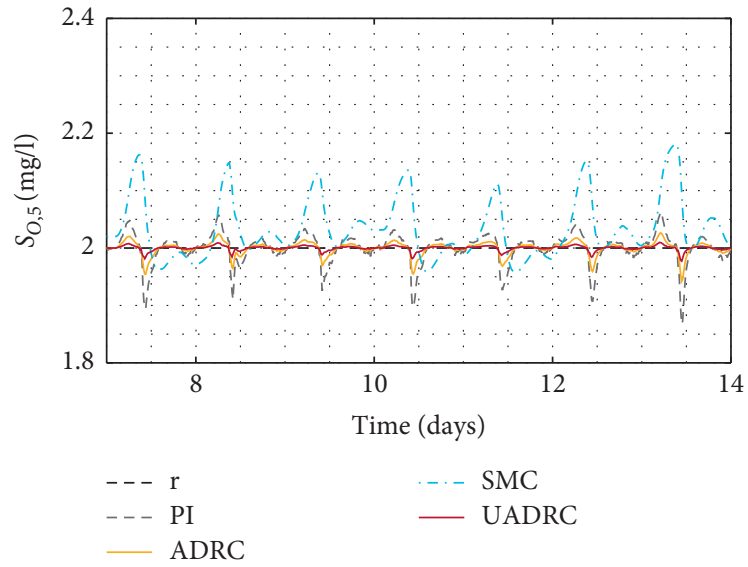

(a)

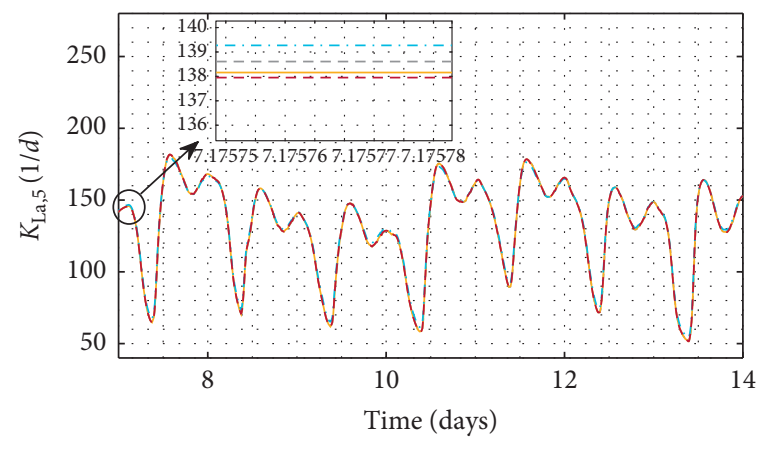

- - PI

ADRC
-.- SMC

- . UADRC

(b)

FIGURE 8: System responses and control signals for a constant set-value (under rain weather). (a) System responses. (b) Control signals.

TABLE 4: Indexes under rain weather.

\begin{tabular}{|c|c|c|c|c|c|c|c|}
\hline & PI & SMC & ADRC & UADRC & $\begin{array}{c}\text { Improvements (UADRC } \\
\text { vs PI) }\end{array}$ & $\begin{array}{l}\text { Improvements (UADRC vs } \\
\text { SMC) }\end{array}$ & $\begin{array}{c}\text { Improvements (UADRC vs } \\
\text { ADRC) }\end{array}$ \\
\hline ISE & 0.109 & 0.080 & 0.031 & 0.027 & $-75.2 \%$ & $-66.3 \%$ & $-12.9 \%$ \\
\hline ITAE & 1.654 & 4.307 & 0.717 & 0.268 & $-83.8 \%$ & $-93.8 \%$ & $-62.6 \%$ \\
\hline OCI & 17128.68 & 17135.86 & 17128.87 & 17128.83 & $+8.8 \times 10^{-4} \%$ & $-4.1 \times 10^{-2} \%$ & $-2.3 \times 10^{-4} \%$ \\
\hline
\end{tabular}

TABLE 5: Indexes under storm weather.

\begin{tabular}{|c|c|c|c|c|c|c|c|}
\hline & PI & SMC & ADRC & UADRC & $\begin{array}{c}\text { Improvements (UADRC } \\
\text { vs PI) }\end{array}$ & $\begin{array}{c}\text { Improvements (UADRC vs } \\
\text { SMC) }\end{array}$ & $\begin{array}{c}\text { Improvements (UADRC vs } \\
\text { ADRC) }\end{array}$ \\
\hline ISE & 0.11 & 008 & 0.032 & 0 & $-75.9 \%$ & $-68.2 \%$ & \\
\hline ITAE & 1.951 & 4.786 & 0.845 & 0.31 & -83 & $-93.4 \%$ & $-62.8 \%$ \\
\hline OCI & 17762.79 & 17767.91 & 17763.00 & 17762.96 & $+9.6 \times 10^{-4} \%$ & $-2.8 \times 10^{-2} \%$ & $-2.3 \times 10^{-4} \%$ \\
\hline
\end{tabular}

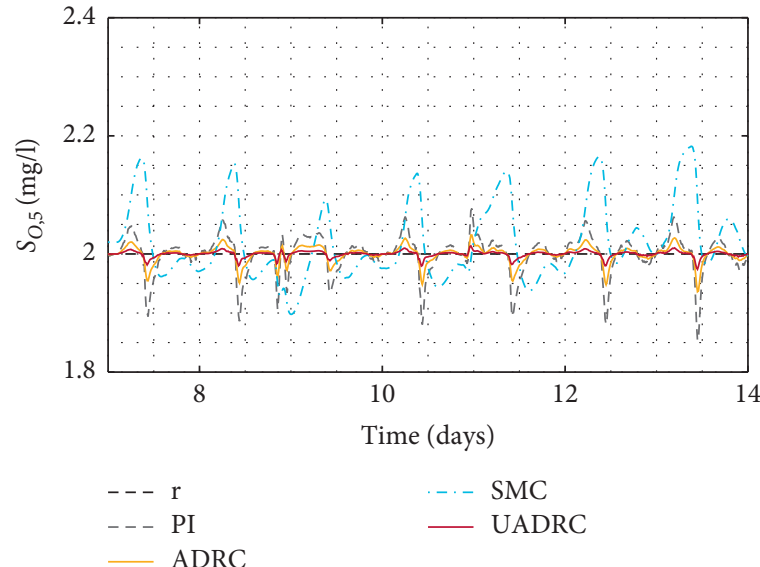

(a)

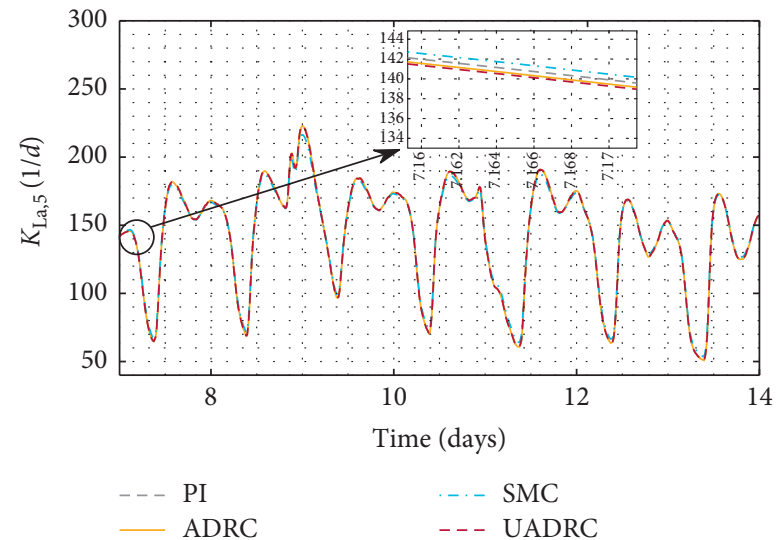

(b)

FiguRE 9: System responses and control signals for a constant set-value (under storm weather). (a) System responses. (b) Control signals. 


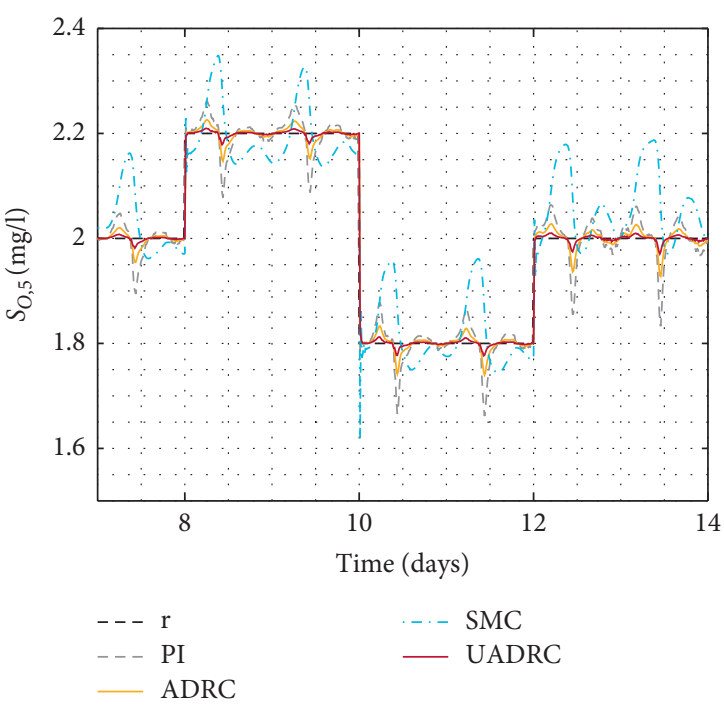

(a)

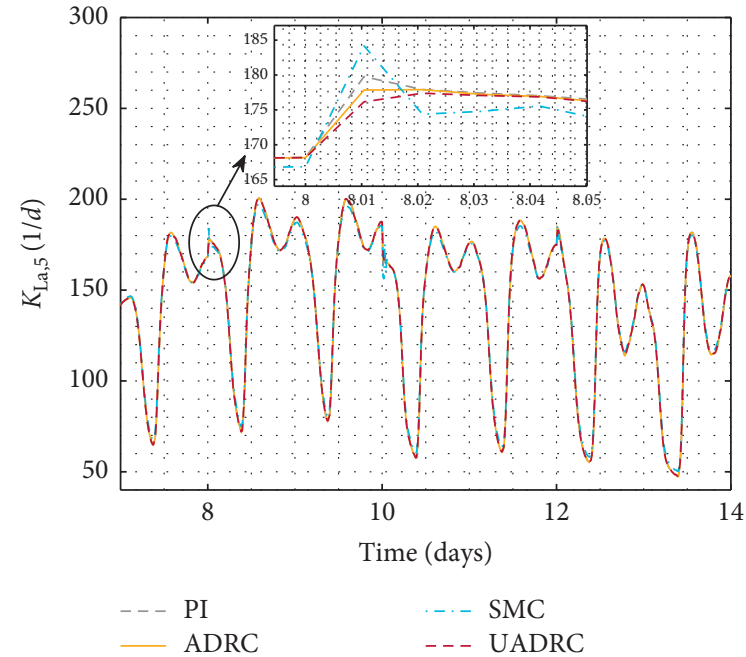

(b)

FiguRE 10: System responses and control signals for the varying set-values (under dry weather). (a) System responses. (b) Control signals.

TABLE 6: Indexes under dry weather (for varying set-values).

\begin{tabular}{lccccccc}
\hline & \multirow{2}{*}{ PI } & \multirow{2}{*}{ SMC } & ADRC & \multirow{2}{*}{ UADRC } & $\begin{array}{c}\text { Improvements (UADRC } \\
\text { vs PI) }\end{array}$ & $\begin{array}{c}\text { Improvements (UADRC vs } \\
\text { Improvements (UADRC vs } \\
\text { ADRC) }\end{array}$ \\
\hline ISE & 0.114 & 0.091 & 0.032 & 0.028 & $-75.4 \%$ & $-69.2 \%$ & $-12.5 \%$ \\
ITAE & 2.118 & 5.149 & 0.924 & 0.365 & $-82.8 \%$ & $-92.9 \%$ & $-60.5 \%$ \\
OCI & 17343.49 & 17348.58 & 17343.70 & 17343.67 & $+1.0 \times 10^{-3} \%$ & $-2.8 \times 10^{-2} \%$ & $-1.7 \times 10^{-4} \%$ \\
\hline
\end{tabular}

$$
r(t)= \begin{cases}2.2 \mathrm{mg} / 1, & 8 \text { days } \leq t<10 \text { days, } \\ 1.8 \mathrm{mg} / 1, & 10 \text { days } \leq t<12 \text { days } \\ 2.0 \mathrm{mg} / 1, & \text { other days. }\end{cases}
$$

4.2.1. Dry Weather. Figure 10 gives out the tracking performance and control signals. From Figure 10(a), one can see clearly that the varying DO concentrations can be tracked effectively by PI, SMC, ADRC, and UADRC. In addition, the UADRC is able to track the varying DO concentrations best, even if the input disturbance from the 7th day exists. Simultaneously, control signals presented in Figure 10(b) show that the UADRC can achieve best response by similar control efforts compared with PI, SMC, and ADRC.

Table 6 presents ISE, ITAE, and OCI values of four controllers. It can be found that, compared with PI, ISE value of the UADRC decreases by 75.4\%, ITAE value decreases by $82.8 \%$, although OCI increases by $1.0 \times 10^{-3} \%$. Simultaneously, by comparison with the sliding-mode controller, ISE value of the UADRC decreases by $69.2 \%$, ITAE value decreases by $92.9 \%$, and the OCI decreases by $2.8 \times 10^{-2} \%$. Additionally, for the ADRC and UADRC, the latter one is able to behave much better than the former one, as a result of minimizing the phase delay between the control signal and system output. Therefore, in the WWTP described by the
BSM1, the UADRC is able to regulate the DO concentration best with similar energy consumption.

4.2.2. Rain Weather. For the rain weather, system responses and control signals are described in Figure 11. It demonstrates that the UADRC can achieve the best tracking performance with nearly the same control efforts when the set-value varies. Additionally, from Table 7, it can be found that, compared with PI and SMC, ISE, and ITAE values of the UADRC have been improved greatly. Simultaneously, by reducing the phase delay between the control signal and system output, the UADRC performs much better than the ADRC. From Table 7, it is also clear that all improvements are obtained by few increasements of the energy consumption.

4.2.3. Storm Weather. System response under storm weather is shown in Figure 12. It also depicts a fact that the UADRC is capable of achieving the best DO concentration tracking. Table 8 lists the ISE, ITAE, and OCI values to confirm the advantage of UADRC. From Table 8, it can be found that, compared with the PI and SMC, ISE and ITAE values of the UADRC are much smaller. Simultaneously, for the reduced phase delay between the control signal and system output, the UADRC responds faster and more accurate than the ADRC. 


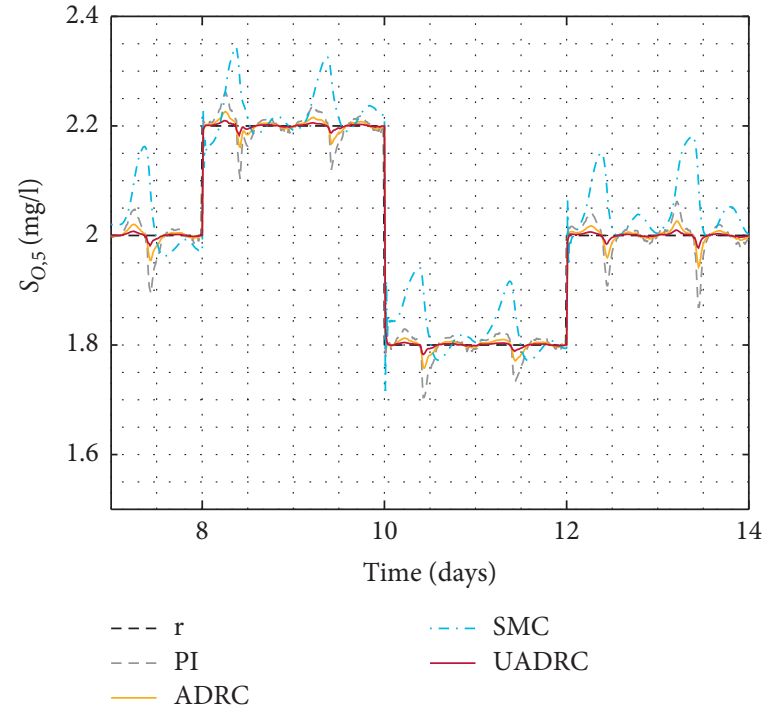

(a)

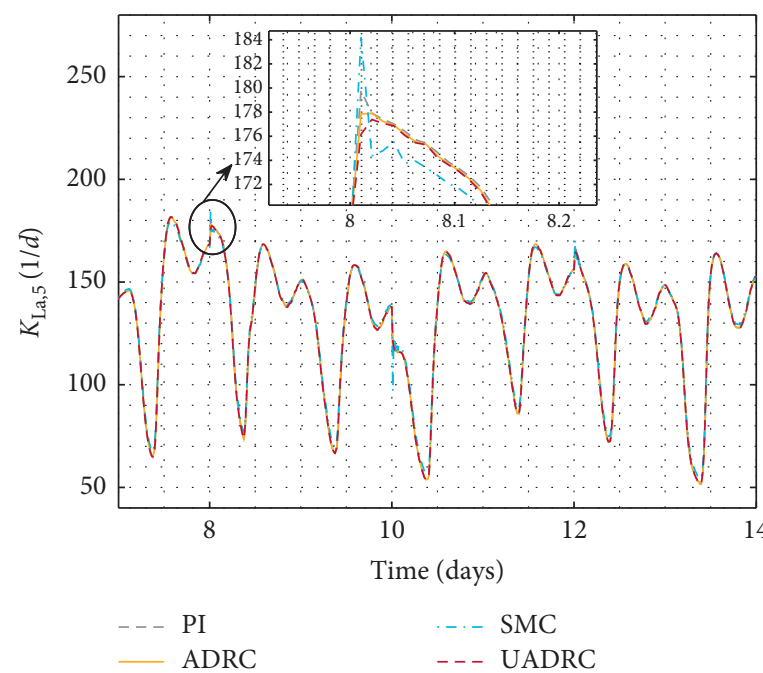

(b)

FiguRe 11: System responses and control signals for the varying set-values (under rain weather). (a) System responses. (b) Control signals.

TABLE 7: Indexes under rain weather (for varying set-values).

\begin{tabular}{lccccccc}
\hline & \multirow{2}{*}{ PI } & \multirow{2}{*}{ SMC } & ADRC & UADRC & $\begin{array}{c}\text { Improvements (UADRC } \\
\text { vs PI) }\end{array}$ & $\begin{array}{c}\text { Improvements (UADRC vs } \\
\text { SMC) }\end{array}$ & $\begin{array}{c}\text { Improvements (UADRC vs } \\
\text { ADRC) }\end{array}$ \\
\hline ISE & 0.110 & 0.081 & 0.032 & 0.028 & $-74.5 \%$ & $-65.4 \%$ & $-12.5 \%$ \\
ITAE & 1.690 & 4.257 & 0.738 & 0.300 & $-82.2 \%$ & $-93.0 \%$ & $-59.3 \%$ \\
OCI & 17129.53 & 17136.63 & 17129.72 & 17129.67 & $+8.2 \times 10^{-4} \%$ & $-4.1 \times 10^{-2} \%$ & $-2.9 \times 10^{-4} \%$ \\
\hline
\end{tabular}

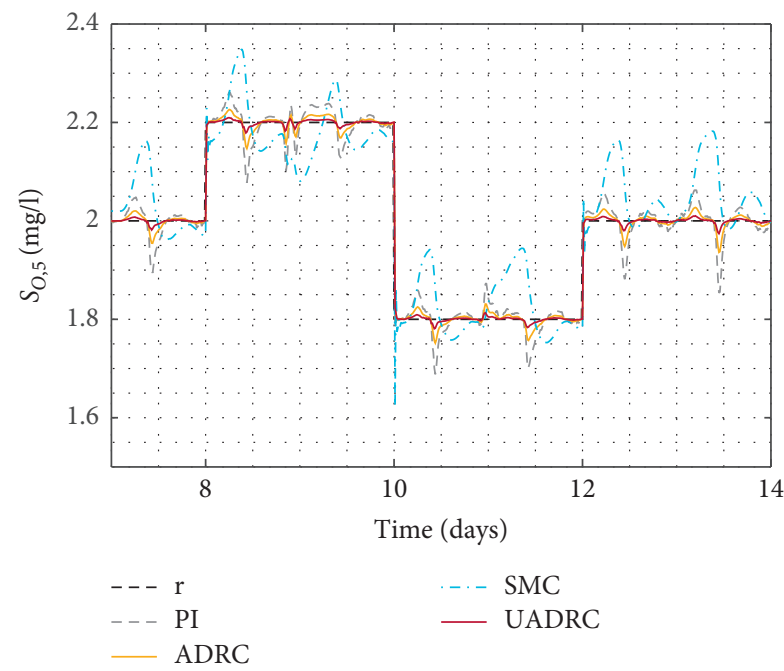

(a)

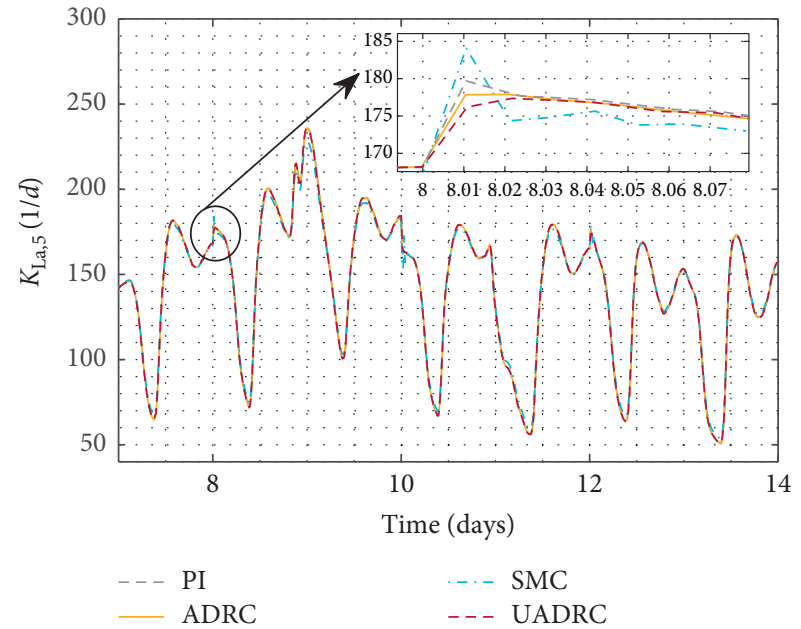

(b)

FIGURE 12: System responses and control signals for the varying set-values (under storm weather). (a) System responses. (b) Control signals.

TABLE 8: Indexes under storm weather (for varying set-values).

\begin{tabular}{|c|c|c|c|c|c|c|c|}
\hline & PI & SMC & ADRC & UADRC & $\begin{array}{c}\text { Improvements (UADRC } \\
\text { vs PI) }\end{array}$ & $\begin{array}{c}\text { Improvements (UADRC vs } \\
\text { SMC) }\end{array}$ & $\begin{array}{c}\text { Improvements (UADRC vs } \\
\text { ADRC) }\end{array}$ \\
\hline ISE & 0.113 & 0 & & & $-75.2 \%$ & $-67.8 \%$ & $-12.5 \%$ \\
\hline ITAE & 1.991 & 4.870 & 0.868 & 0.346 & $-82.6 \%$ & $-92.9 \%$ & $-60.1 \%$ \\
\hline OCI & 17763.56 & 17768.58 & 17763.78 & 17763.74 & $+1.0 \times 10^{-3} \%$ & $-2.7 \times 10^{-2} \%$ & $-2.3 \times 10^{-4} \%$ \\
\hline
\end{tabular}


TABle 9: Parameters of the UADRC ( $\omega_{n}$ is fixed).

\begin{tabular}{cccccc}
\hline & $\tau_{n}$ & $\omega_{o}$ & $b_{0}$ & $\omega_{n}^{2}$ \\
\hline 300 & 400 & 500 & 800 & 8 & 1600 \\
\hline
\end{tabular}

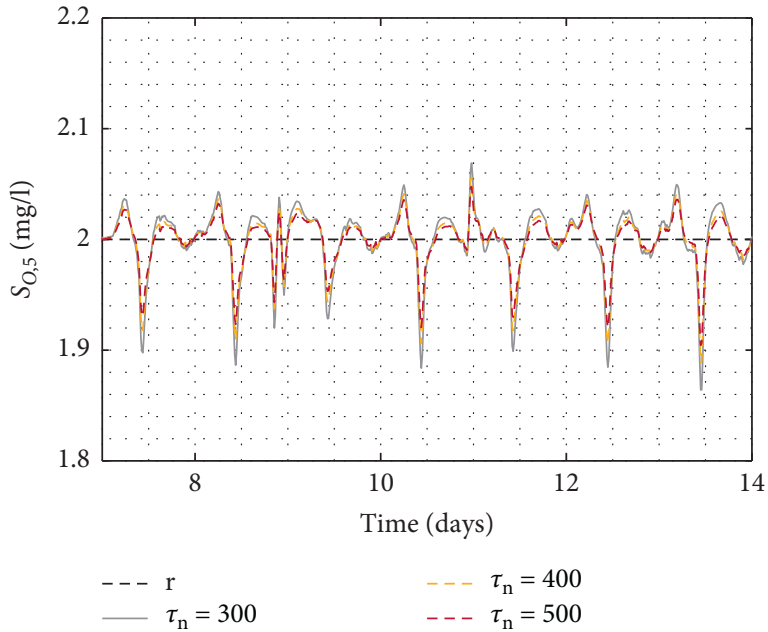

(a)

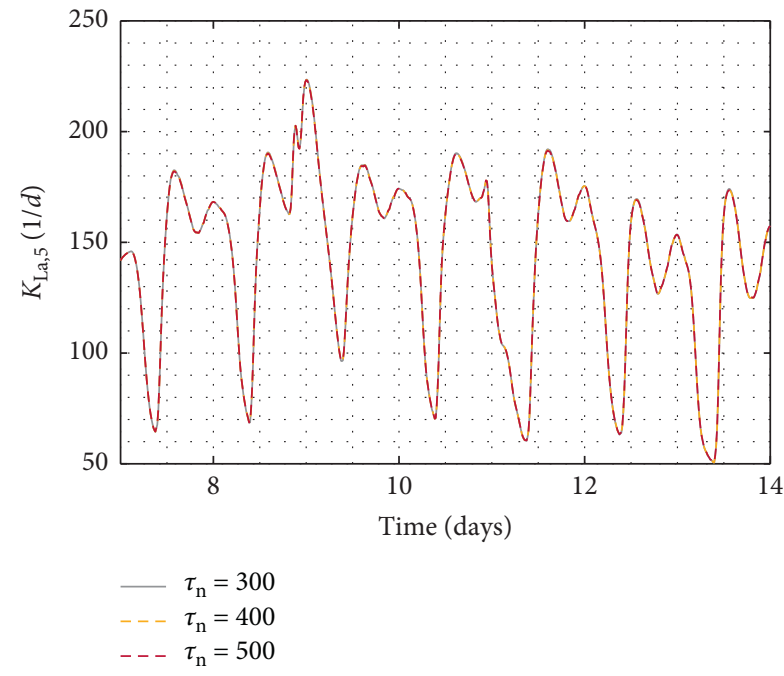

(b)

FIgURE 13: System responses and control signals under storm weather ( $\omega_{n}$ is fixed). (a) System responses. (b) Control signals.

In the above sections, one can see clearly that as a result of reducing the phase delay between the control input and system output, the UADRC performs best among four controllers. Next, relationship between the closed-loop system performance and tunable parameters of the UADRC is discussed.

4.3. Discussion. Tunable parameters of the UADRC are $\tau_{n}, \omega_{n}, b_{0}, \omega_{o}$. According to the results obtained in Section 3, the tracking error of the UADRC can be suppressed effectively by increasing $\tau_{n}$ or improving the estimation ability of an ESO. For $\omega_{n}$, it should be made a compromise. In this part, influence of $\omega_{n}$ and $\tau_{n}$ on DO concentration control is discussed. Two scenarios are considered. First, fixing $\omega_{n}$ and increasing $\tau_{n}$. Then, fixing $\tau_{n}$, and increasing $\omega_{n}$. The influence of $\omega_{n}$ and $\tau_{n}$ can be seen clearly. For complexity of the storm weather, it is considered in this section.

4.3.1. Fixing $\omega_{n}$ and Increasing $\tau_{n}$. Here, the input disturbance $(5 \sin (5 t))$ is also used, and the set-value is taken to be $r(t)$ shown in (33). Parameters of the UADRC are listed in Table $9 . \omega_{n}$ is fixed to be 40 , and values of $\tau_{n}$ are increasing.

System responses and control signals are given in Figure 13. Table 10 lists ISE and ITAE values to show the trend of tracking error and settling time of the UADRC when $\tau_{n}$ is increased. From Figure 13(a), it can be seen that, as $\tau_{n}$ increases, tracking errors become smaller. The fact can also be found from Table 10. It is obvious that both ISE and ITAE values decrease as $\tau_{n}$ increased. It confirms that both tracking error and settling time become smaller when $\tau_{n}$ is increased.
TABLE 10: Indexes under storm weather ( $\omega_{n}$ is fixed).

\begin{tabular}{lccc}
\hline & & $\tau_{n}$ & \\
& 300 & 400 & 500 \\
\hline ISE & 0.0155 & 0.0128 & 0.0115 \\
ITAE & 1.7651 & 1.4261 & 1.2155 \\
\hline
\end{tabular}

TABLE 11: Parameters of the UADRC ( $\tau_{n}$ is fixed).

\begin{tabular}{|c|c|c|c|c|c|}
\hline & $\omega_{n}^{2}$ & & $\omega_{o}$ & $b_{0}$ & $\tau_{n}$ \\
\hline 4900 & 6400 & 8100 & 800 & 8 & 900 \\
\hline
\end{tabular}

4.3.2. Fixing $\tau_{n}$ and Increasing $\omega_{n}$. Parameters of the UADRC are shown in Table 11. $\tau_{n}$ is fixed to be 900 , and $\omega_{n}$ is increased.

System responses and control signals are shown in Figure 14. Table 12 presents the tendency of the tracking error and settling time of the UADRC with an increasing $\omega_{n}$. Numerical results indicate that, when $\omega_{n}$ is increased, ISE value increases, system response rate becomes faster, and ITAE value decreases.

So far, influence of $\tau_{n}$ and $\omega_{n}$ is obvious. It coincides with the results obtained in Section 3. Thus, it is easier for engineers to take good advantage of the UADRC to regulate the DO concentration in a WWTP.

In addition, from the UADRC structure (see Figure 6) presented in Section 3, one can find that based on an ESO and the UC, the UADRC is an open structure for a designer to construct desired closed-loop system dynamics. Therefore, it is a flexible design approach to satisfy engineering requirements. Probably, the UADRC structure is a promising way to 


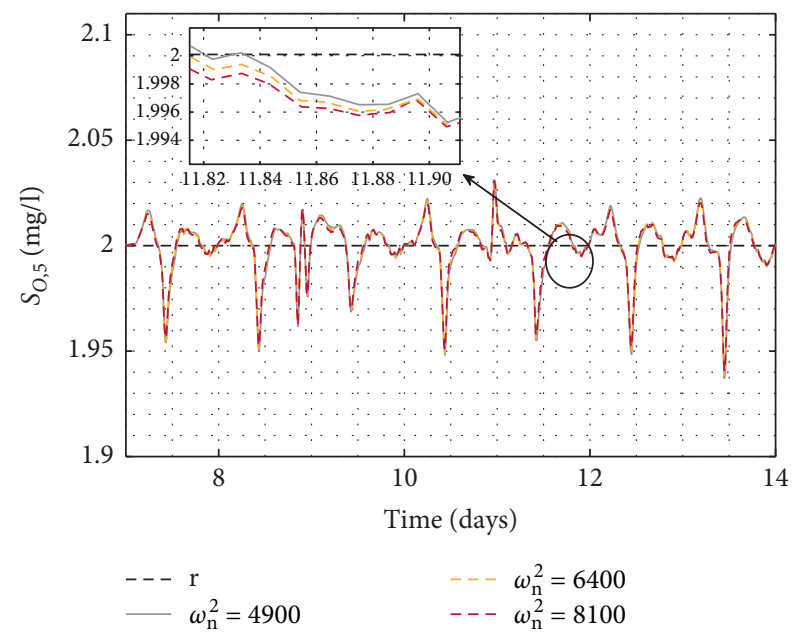

(a)

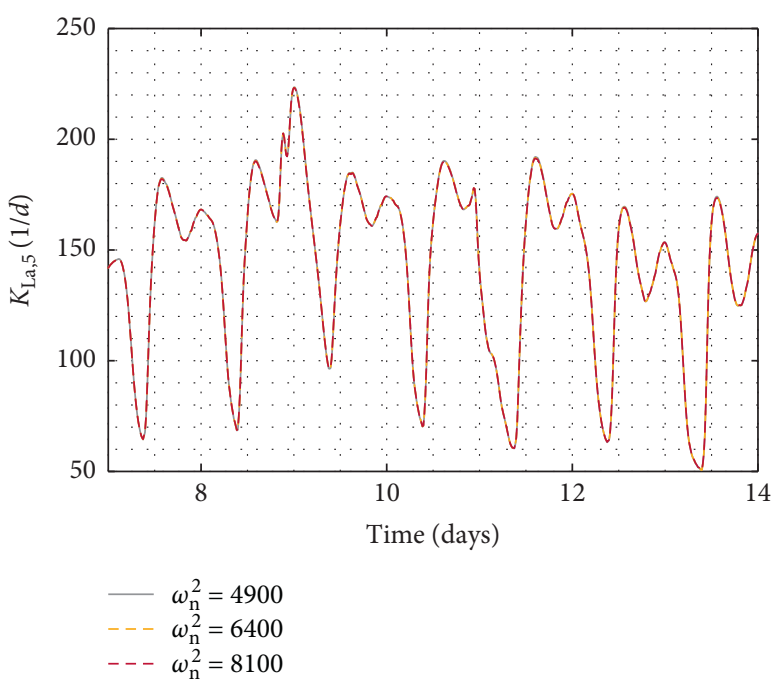

(b)

Figure 14: System responses and control signals under storm weather ( $\tau_{n}$ is fixed). (a) System responses. (b) Control signals.

TABLE 12: Indexes under dry weather $\left(\tau_{n}\right.$ is fixed).

\begin{tabular}{lccc}
\hline & & $\omega_{n}^{2}$ & \\
& 4900 & 6400 & 8100 \\
\hline ISE & 0.0112 & 0.0113 & 0.0115 \\
ITAE & 0.7693 & 0.7396 & 0.7056 \\
\hline
\end{tabular}

combine most existing control techniques to obtain satisfactory performance, as long as the ESO works as desired.

\section{Conclusions}

Kinds of uncertainties and disturbances exist in a WWTP. Keep the DO concentration in a desired level is always a challenge. For improving the set-value tracking and the disturbance rejection ability of a closed-loop system, based on the key point of ADRC and UC, a UADRC is constructed to control the DO concentration in a WWTP. By minimizing the phase delay between the control input and the system output, system response becomes faster. Based on the UC, system response becomes more accurate. By virtue of an ESO, system performance becomes more robust. Numerical results based on the BSM1 show that the UADRC works much better than SMC, ADRC, and the PI with suggested parameters. It confirms the advantage of the proposed UADRC. For the future research, the UADRC should be verified in a real WWTP.

\section{Data Availability}

Data supporting the findings of this study are available from the corresponding author upon request.

\section{Conflicts of Interest}

The authors declare that they have no conflicts of interest.

\section{Acknowledgments}

This work was supported by the Key program of Beijing Municipal Education Commission (KZ201810011012), National Natural Science Foundation of China (61873005), and Support Project of High-level Teachers in Beijing Municipal Universities in the Period of 13th Five-year Plan (CIT\&TCD201704044).

\section{References}

[1] World Economic Forum, "The global risks report 2019," World Economic Forum, Cologny, Switzerland, 2019.

[2] Y. Qian, H. Dong, X. Tian et al., "A review of the research on China's water footprint responding to water crisis," Ecological Economy, vol. 34, no. 7, pp. 162-166, 2018.

[3] N. Mahjouri and E. Pourmand, "A social choice-based methodology for treated wastewater reuse in urban and suburban areas," Environmental Monitoring and Assessment, vol. 189, no. 7, p. 325, 2017.

[4] M. A. Shannon, P. W. Bohn, M. Elimelech, J. G. Georgiadis, B. J. Mariñas, and A. M. Mayes, "Science and technology for water purification in the coming decades," Nature, vol. 452, no. 7185, pp. 301-310, 2008.

[5] J. Qiao, W. Fu, and H. Han, "Dissolved oxygen control method based on self-organizing T-S fuzzy neural network," CIESC Journal, vol. 67, no. 3, pp. 960-966, 2016.

[6] A. Zhang, X. Yin, S. Liu, J. Zeng, and J. Liu, "Distributed economic model predictive control of wastewater treatment plants," Chemical Engineering Research and Design, vol. 141, no. 1, pp. 144-155, 2019.

[7] I. Santín, C. Pedret, and R. Vilanova, "Applying variable dissolved oxygen set point in a two level hierarchical control structure to a wastewater treatment process," Journal of Process Control, vol. 28, no. 4, pp. 40-55, 2015.

[8] H. Han, X. Wu, and J. Qiao, "A self-organizing sliding-mode controller for wastewater treatment processes," IEEE Transactions on Control Systems Technology, vol. 27, no. 4, pp. 1480-1491, 2019. 
[9] K. B. Newhart, R. W. Holloway, A. S. Hering, and T. Y. Cath, "Data-driven performance analyses of wastewater treatment plants: a review," Water Research, vol. 157, no. 6, pp. 498-513, 2019.

[10] H.-g. Han, L. Zhang, and J.-f. Qiao, "Data-based predictive control for wastewater treatment process," IEEE Access, vol. 6, pp. 1498-1512, 2018.

[11] C. Muñoz, H. Young, C. Antileo, and C. Bornhardt, "Sliding mode control of dissolved oxygen in an integrated nitrogen removal process in a sequencing batch reactor (SBR)," Water Science and Technology, vol. 60, no. 10, pp. 2545-2553, 2009.

[12] D. Selisteanu, E. Petre, and V. B. Rasvan, "Sliding mode and adaptive sliding-mode control of a class of nonlinear bioprocesses," International Journal of Adaptive Control and Signal Processing, vol. 21, no. 8-9, pp. 795-822, 2007.

[13] R. Madonski, M. Nowicki, and P. Herman, "Application of active disturbance rejection controller to water supply system," in Proceedings of the 33rd Chinese Control Conference, Nanjing, China, July 2014.

[14] W. Wei, M. Zuo, W. Li et al., "Control of dissolved oxygen for a wastewater treatment process by active disturbance rejection control approach," Control Theory \& Applications, vol. 35, no. 1, pp. 24-30, 2018.

[15] R. Madonski, M. Nowicki, and P. Herman, "Practical solution to positivity problem in water management systems-an ADRC approach," in Proceedings of the 2016 American Control Conference, Boston, MA, USA, July 2016.

[16] M. Sadeghassadi, C. J. B. Macnab, B. Gopaluni, and D. Westwick, "Application of neural networks for optimalsetpoint design and MPC control in biological wastewater treatment," Computers \& Chemical Engineering, vol. 115, no. 7, pp. 150-160, 2018.

[17] J.-F. Qiao, G.-T. Han, H.-G. Han, C.-L. Yang, and W. Li, "Decoupling control for wastewater treatment process based on recurrent fuzzy neural network," Asian Journal of Control, vol. 21, no. 4, pp. 1-11, 2019.

[18] Q. M. Zhu and L. Z. Guo, "A pole placement controller for non-linear dynamic plants," Proceedings of the Institution of Mechanical Engineers, Part I: Journal of Systems and Control Engineering, vol. 216, no. 6, pp. 467-476, 2002.

[19] Q. Zhu, W. Zhang, J. Na, and B. Sun, "U-model based control design framework for continuous-time systems," in Proceedings of the 38th Chinese Control Conference, Guangzhou, China, July 2019.

[20] J. Han, "From PID to active disturbance rejection control," IEEE Transactions on Industrial Electronics, vol. 56, no. 3, pp. 900-906, 2009.

[21] J. Alex, L. Benedetti, J. Copp et al., Benchmark Simulation Model No. 1 (bsm1), Lund University Sweden, Lund, Sweden, 2008.

[22] J. Copp, The COST Simulation Benchmark: Description and Simulator Manual, Official Publications of the European Community, Brussels, Belgium, 2001.

[23] J.-F. Qiao, Y. Hou, and H.-G. Han, "Optimal control for wastewater treatment process based on an adaptive multiobjective differential evolution algorithm," Neural Computing and Applications, vol. 31, no. 7, pp. 2537-2550, 2019.

[24] M.-J. Lin and F. Luo, "Adaptive neural control of the dissolved oxygen concentration in WWTPs based on disturbance observer," Neurocomputing, vol. 185, pp. 133-141, 2016.

[25] W. Wei, W. Xue, and D. Li, "On disturbance rejection in magnetic levitation," Control Engineering Practice, vol. 82, pp. 24-35, 2019.

[26] Q. Zheng, Z. Chen, and Z. Gao, "A practical approach to disturbance decoupling control," Control Engineering Practice, vol. 17, no. 9, pp. 1016-1025, 2009. 